\title{
Severe Impairment in Early Host Defense against Candida albicans in Mice Deficient in Myeloperoxidase
}

\author{
YASUAKI ARATANI, ${ }^{1,2 *}$ HIDEKI KOYAMA, ${ }^{1}$ SEI-ICHIRO NYUI, ${ }^{1}$ KAZUO SUZUKI, ${ }^{3}$ \\ FUMIAKI KURA, ${ }^{4}$ AND NOBUYO MAEDA ${ }^{2}$
}

Kihara Institute for Biological Research and Graduate School of Integrated Science, Yokohama City University, Totsuka-ku, Yokohama 244-0813, ${ }^{1}$ and Departments of Bioactive Molecules ${ }^{3}$ and Bacteriology, ${ }^{4}$ National Institute of Infectious Diseases, Toyama 1-23-1, Shinjuku-ku, Tokyo 162-8640, Japan, and Department of Pathology and Laboratory Medicine, University of North Carolina, Chapel Hill, North Carolina 27599-7525 2

Received 12 August 1998/Returned for modification 16 September 1998/Accepted 23 December 1998

\begin{abstract}
Myeloperoxidase (MPO) catalyzes the reaction of hydrogen peroxide with chloride ion to produce hypochlorous acid $(\mathrm{HOCl})$, which is used for microbial killing by phagocytic cells. Despite the important role of MPO in host defense, however, MPO deficiency is relatively common in humans, and most of these individuals are in good health. To define the in vivo role of MPO, we have generated by gene targeting mice having no MPO activity in their neutrophils and monocytes. The mice without MPO developed normally, were fertile, and showed normal clearance of intraperitoneal Staphylococcus aureus. However, they showed increased susceptibility to pneumonia and death following intratracheal infection with Candida albicans. Furthermore, the lack of MPO significantly enhanced the dissemination of intraperitoneally injected $C$. albicans into various organs during the first 7 days. Thus, MPO is important for early host defense against fungal infection, and the inability to generate HOCl cannot be compensated for by other oxygen-dependent systems in vivo in mice. The mutant mice serve as a model for studying pulmonary and systemic candidiasis.
\end{abstract}

Neutrophil granulocytes are the first line of defense against invading microorganisms such as bacteria, viruses, and fungi. Apart from other defense mechanisms (4), the generation of reactive oxygen compounds plays an important role in defense. Myeloperoxidase (MPO; EC 1.11.1.7) is a cationic heme-containing enzyme found in primary azurophilic granules of neutrophils and primary lysosomes of monocytes $(3,23)$. In chemoattractant-activated neutrophils, MPO transforms hydrogen peroxide $\left(\mathrm{H}_{2} \mathrm{O}_{2}\right)$ generated during the oxidative burst to highly cytotoxic hypochlorous acid $(\mathrm{HOCl})$ in the presence of chloride ion $\left(\mathrm{Cl}^{-}\right)(2)$. This $\mathrm{MPO}-\mathrm{H}_{2} \mathrm{O}_{2}-\mathrm{Cl}^{-}$system appears to be important in microbial killing by neutrophils $(6,22,24,35,37$, $52,53)$. It may also be involved in their cytotoxicity against tumor cells $(7,31)$ and in tissue damage at sites of inflammation, where neutrophils can release both MPO and $\mathrm{H}_{2} \mathrm{O}_{2}(5$, 10-12, 18).

Both human MPO and murine MPO are encoded by a single gene (Mpo in mice) $(39,54)$, and the respective genes have been cloned and sequenced $(19,46)$. MPO is synthesized in bone marrow during the late myeloblastic and promyelocytic stages of myeloid maturation (55). MPO isolated from mature human neutrophils has a molecular mass of $150 \mathrm{kDa}$ and is composed of two heavy chains $(59 \mathrm{kDa})$ and two light chains (14 kDa) $(1,36,51)$.

Hereditary MPO deficiency appears to be the most common biochemical defect of neutrophils and is not geographically restricted $(6,22,31,34,37,40,41,43)$. An estimated prevalence of 1 of 2,000 to 4,000 individuals has been reported in the United States (37) and Italy (8). Considering the important role of $\mathrm{HOCl}$ for effective killing of microorganisms, it is surprising that most individuals with MPO deficiency are healthy. This fact stands in marked contrast to the situation for patients

* Corresponding author. Mailing address: Kihara Institute for Biological Research, Yokohama City University, Maioka-cho 641-12, Totsuka-ku, Yokohama 244-0813, Japan. Phone: 81-45-820-1907. Fax: 8145-820-1901. E-mail: yaratani@yokohama-cu.ac.jp. with chronic granulomatous disease (CGD), in whom granulocytes are deficient in NADPH oxidase and consequently do not produce any reactive oxygen compound. Patients with CGD typically have clinical symptoms early in life and recurrent infections that can lead to death during childhood. However, an increased susceptibility to infections, particularly those caused by Candida albicans, has been reported for some MPOdeficient patients $(6,29,35,37)$. In these patients, who were also affected with diabetes, it was not determined whether the infections were due to MPO deficiency or whether other disorders were also relevant. An interplay of other mechanisms seems to compensate for the inability of MPO-deficient cells to generate $\mathrm{HOCl}$ from $\mathrm{H}_{2} \mathrm{O}_{2}$.

Here, we report the generation of mice with a nonfunctional allele for MPO by targeted homologous recombination with mouse ES cells. The enzyme activity of MPO is absent in neutrophils and monocytes from homozygous mutant mice. These mice also exhibit increased susceptibility to infection with C. albicans.

\section{MATERIALS AND METHODS}

Cloning of the mouse $\mathrm{Mpo}$ gene and construction of a targeting vector. A 396-bp DNA fragment containing exons 5 and 6 of the mouse Mpo gene was amplified from ES cell genomic DNA with primers designed from the published sequence (46). This fragment was used as a probe to screen a $\lambda$ phage library made from strain 129 mouse genomic DNA. A clone containing a part of the Mpo gene was isolated, and its restriction map and a partial nucleotide sequence were determined. For constructing the targeting vector (Fig. 1A), a 2.2-kb fragment containing exons 1 to 5 and a $5.9-\mathrm{kb}$ fragment containing exons 8 to 11 were used as the two homologous arms flanking the neo gene. The herpes simplex virus (HSV) thymidine kinase (TK) gene was positioned downstream of the longer arm (32).

Gene targeting and production of mice by use of modified ES cells. BK4 cells, a subclone of E14TG2a derived from strain 129/Ola mice, were cultured on feeder cells as described previously (44). The targeting vector mentioned above was linearized with Not I and introduced into ES cells by electroporation. Colonies doubly resistant to G418 $(200 \mu \mathrm{g} / \mathrm{ml})$ and ganciclovir $(2 \mu \mathrm{M})$ were screened for homologous recombination by Southern blot analysis following digestion of genomic DNA with $B g l$ II by use of the 722-bp PCR-amplified fragment containing exon 5 of the Mpo gene as a probe. The resulting cells with a disrupted Mpo gene were injected into blastocysts to obtain chimeras as described previously 

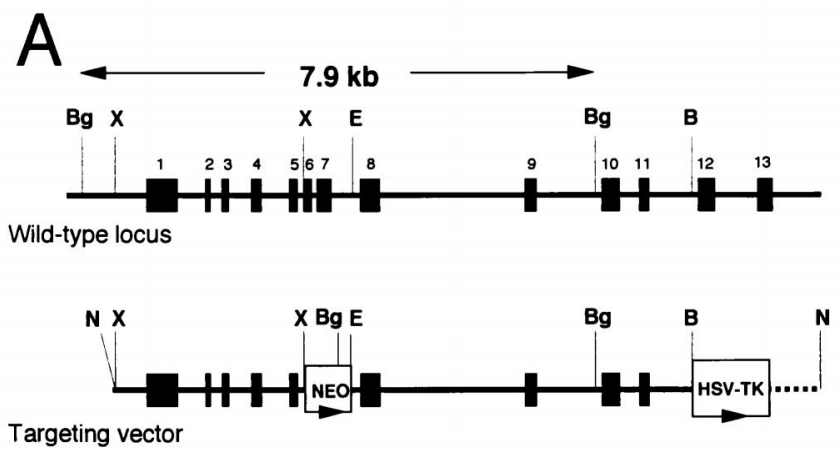

Targeting vector
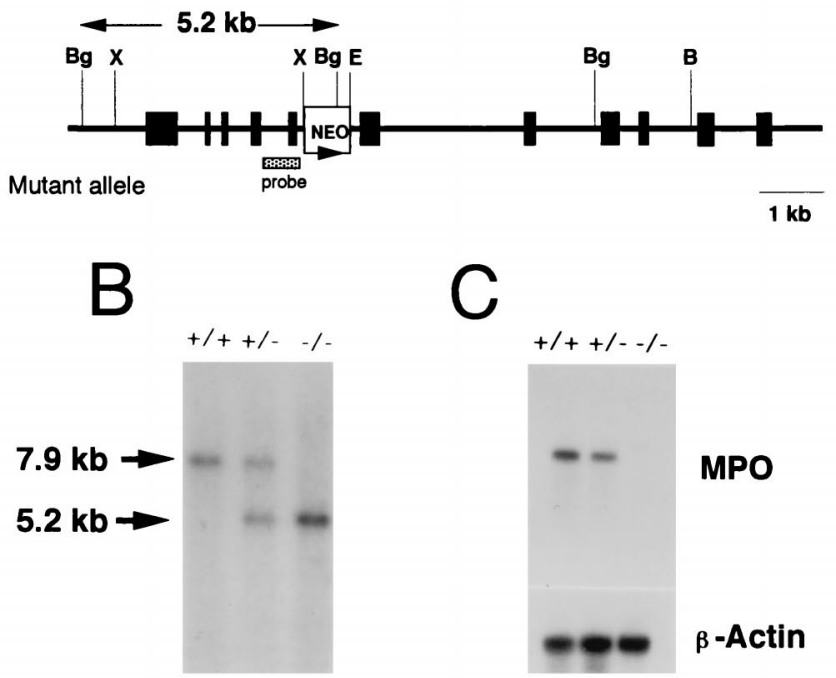

FIG. 1. Targeted disruption of the mouse Mpo gene and germ line transmission of the disrupted allele. (A) Structures of the wild-type Mpo locus, targeting vector, and mutant allele generated by homologous recombination. Exons are shown as black boxes and numbered. The targeting vector contains the neo gene (NEO) in place of the $X b a \mathrm{I}-E c o$ RI region containing exons 6 and 7. The HSV TK gene is attached to the end of the region of homology. The broken line indicates the vector sequence. The lengths of diagnostic BglII restriction fragments and the location of a probe used for Southern blot analysis are shown. B, $B a m \mathrm{HI}$; Bg, BglII; E, EcoRI; N, NotI; X, XbaI. (B) Southern blot analysis. Genomic DNA was isolated from tail snips of the offspring of a heterozygous cross, digested with $B g l I I$, and analyzed by Southern hybridization with the DNA probe indicated in panel A. Genotypes are indicated as wild-type $(+/+)$, heterozygous $(+/-)$, and homozygous $(-/-)$ mice. (C) Northern blot analysis of bone marrow mRNA. Total RNA $(10 \mu \mathrm{g})$ isolated from bone marrow of wildtype $(+/+)$, heterozygous mutant $(+/-)$, and homozygous mutant $(-/-)$ mice was electrophoresed, blotted, and hybridized to a human $M P O$ cDNA probe. The amounts of RNA loaded are indicated by hybridization to a cDNA probe for chicken $\beta$-actin.

$(25,47)$. Animals classified as chimeric by coat color were mated with strain C57BL/6 mice, and $\mathrm{F}_{1}$ animals heterozygous for the disrupted Mpo gene were obtained. Interbreeding of heterozygous offspring was used to produce mice homozygous for the modified MPO allele.

Northern blotting of bone marrow cells. Total RNA was isolated from bone marrow cells with TRIzol (Gibco BRL) as recommended by the manufacturer. Each sample $(10 \mu \mathrm{g})$ was electrophoresed in a $2.2 \mathrm{M}$ formaldehyde- $1 \%$ agarose gel, transferred to a Hybond nylon membrane (Amersham Corp.), and probed with a 2.2-kb PstI fragment of a human $M P O$ cDNA vector (pH17) (17) containing exons 2 through 12 of the $M P O$ gene. This fragment is $85 \%$ identical to that in mouse cDNA. A cDNA clone for chicken $\beta$-actin was used as a probe to evaluate the amount of mRNA loaded. mRNA levels were estimated by densitometric analysis of autoradiograms after serial exposures.

Cell counting and measurement of MPO activity. Blood was drawn from the retro-orbital plexus of mice into EDTA-containing tubes. Blood cell analysis was carried out by flow cytometry with Technicon $\mathrm{H}-1$ by the method recommended by the manufacturer. Briefly, separation of leukocytes was performed by peroxidase staining and simultaneous measurement of light scattering (Perox-Chan- nel). For peroxidase staining, erythrocytes were lsyed in the Technicon H-1integrated Perox-Chamber, and leukocytes were fixed with formalin and stained for peroxidase with $\mathrm{H}_{2} \mathrm{O}_{2}$ and 4-chloro-1-naphthol as a chromogen. The cell distribution pattern was plotted by a so-called leukogram with peroxidase activity on the $x$ axis and light scattering on the $y$ axis and was analyzed by a multispecies software program developed for animal blood samples. If intracellular MPO activity decreases, neutrophils and monocytes shift to the left.

Thioglycolate-induced peritonitis. Mice were injected intraperitoneally with 1 $\mathrm{ml}$ of $3 \%$ fluid thioglycolate medium (Difco). After $4 \mathrm{~h}$, peritoneal exudate cells were harvested by peritoneal lavage with $20 \mathrm{ml}$ of phosphate-buffered saline (PBS). Total cell numbers were determined with a hemocytometer. The percentage of neutrophils was determined by microscopic examination of Wright-Giemsa-stained samples.

Cytochemical and biochemical determination of MPO activity. Isolated neutrophil-rich peritoneal exudate cells were stained for MPO activity with the 3,3',5,5'-tetramethylbenzidine (TMB) liquid substrate system from Sigma (St. Louis, Mo.) following formalin-acetone fixation of the cells. Briefly, oxidation of the substrate TMB in MPO-positive cells yields a blue insoluble reaction product which is visualized by light microscopy. MPO activity was quantitatively measured by the method of Suzuki et al. (45) with some modifications. Peritoneal exudate neutrophils were adjusted to $5 \times 10^{6} \mathrm{cells} / \mathrm{ml}$ and incubated with $N$ formyl-Met-Leu-Phe $(1 \mu \mathrm{M})$ and cytochalasin $\mathrm{B}(5 \mu \mathrm{g} / \mathrm{ml})$ for $10 \mathrm{~min}$ at $37^{\circ} \mathrm{C}$. Triton X-100 (final concentration, $0.1 \%$ ) was added to the cell suspensions for total MPO release. Aliquots of the cell extracts were incubated with the TMB liquid substrate system, and the oxidized product was detected spectrophotometrically. The activity was expressed as the initial rate of increase in the absorbance at $655 \mathrm{~nm}$.

Generation of $\mathrm{HOCl}$ and $\mathrm{O}_{2}{ }^{-}$from neutrophils. $\mathrm{HOCl}$ generation by peritoneal exudate neutrophils was measured by the chlorination of monochlorodimedon (MCD) (21). Peritoneal exudate cells $\left(2 \times 10^{6} / \mathrm{ml}\right)$ were incubated in PBS containing $1 \mathrm{mM} \mathrm{CaCl}, 0.5 \mathrm{mM} \mathrm{MgCl}, 5 \mathrm{mM}$ glucose, $100 \mathrm{ng}$ of phorbol myrisate acetate (PMA) per ml, and $20 \mu \mathrm{M} \mathrm{MCD}$ at $37^{\circ} \mathrm{C}$ for $20 \mathrm{~min}$. At the end of this period, samples were ice chilled and centrifuged at $12,000 \times g$ for $5 \mathrm{~min}$. The activity in supernatants of reaction mixtures with or without cells was measured at $290 \mathrm{~nm}$. The amount of $\mathrm{HOCl}$ generated was calculated by use of a molar linear absorption coefficient of $19,000 \mathrm{M}^{-1} / \mathrm{cm}$ (16).

$\mathrm{O}_{2}{ }^{-}$generation was determined as the superoxide dismutase (SOD)-inhibitable reduction of cytochrome $c(14)$. Cytochrome $c(40 \mu \mathrm{M})$ with or without 20 $\mu \mathrm{g}$ of SOD per $\mathrm{ml}$ was added to peritoneal exudate cells $\left(2 \times 10^{6} / \mathrm{ml}\right)$ that had been stimulated with $100 \mathrm{ng}$ of PMA per $\mathrm{ml}$ at $37^{\circ} \mathrm{C}$ for $5 \mathrm{~min}$, and $\mathrm{O}_{2}{ }_{2}^{-}$ generation in the samples was continuously measured for another $5 \mathrm{~min}$ at 550 $\mathrm{nm}$ with a spectrophotometer. $\mathrm{O}_{2}{ }^{-}$generated from the cells was calculated as the difference between levels in SOD-containing samples and those in samples not containing SOD by use of an absorption coefficient of $21,000 \mathrm{M}^{-1} / \mathrm{cm}$ (14).

Experimental infections with C. albicans and Staphylococcus aureus. Stock cultures of C. albicans (ATCC 18804) were cultured on $2 \%$ agar slant medium (pH 6.4) containing $83 \mathrm{mM}$ glucose, $2 \mathrm{mM} \mathrm{MgSO}{ }_{4} \cdot 7 \mathrm{H}_{2} \mathrm{O}, 7.4 \mathrm{mM} \mathrm{KH} \mathrm{KO}_{4}$, $0.5 \%$ Polypeptone, and $0.2 \%$ yeast extract for 10 days at $37^{\circ} \mathrm{C}$. Blastoconidia of C. albicans grown on the slant were transferred to $1.2 \%$ agar plates containing 28 $\mathrm{mM}$ glucose and $0.2 \%$ Polypeptone. After cultivation for 2 days at $37^{\circ} \mathrm{C}$, the blastoconidia were harvested in sterile saline. The number of fungi was counted with a hemocytometer and adjusted to $2 \times 10^{8} \mathrm{cells} / \mathrm{ml}$; the viable number was also determined by plating the diluted samples on agar plates. Wild-type, heterozygous, and homozygous mutant mice were injected by the intratracheal route with $0.02 \mathrm{ml}$ of the fungal suspension. At $0.5,20,80$, and $120 \mathrm{~h}$ after the challenge, the organs were removed aseptically and homogenized in sterile saline. At least five mice were used per group. Aliquots of the homogenates were plated in duplicate on agar plates with Guanofuracin-Sabouraud medium (Eiken Chemical Co., Tokyo, Japan) and incubated for $48 \mathrm{~h}$ at $37^{\circ} \mathrm{C}$. The number of viable C. albicans was calculated from the number of colonies grown on the plates and was expressed in CFU. Data were recorded as the mean $\log _{10} \mathrm{CFU}$ per organ.

In studies of systemic infections, wild-type and homozygous mutant mice were injected intraperitoneally with $4 \times 10^{6}$ cells of $C$. albicans. Seven days later, the organs were removed, homogenized, and plated on agar plates as described above. Five mice were used per group.

For intraperitoneal infection with $S$. aureus, mice were injected intraperitoneally with $0.1 \mathrm{ml}$ of a suspension $\left(7 \times 10^{8} / \mathrm{ml}\right)$ of $S$. aureus (FDA209P) that had been grown for $24 \mathrm{~h}$ on a plate with Trypticase soy agar at $37^{\circ} \mathrm{C}$. Twenty-four and $48 \mathrm{~h}$ later, peritoneal exudate fluid was harvested with PBS, diluted, and cultured for viable S. aureus on Trypticase soy agar at $37^{\circ} \mathrm{C}$. Three to five mice of different genotypes were studied at each time point.

Preparation of sections and slides. Lungs were fixed in a buffered $4 \%$ paraformaldehyde solution, dehydrated in ethanol, and embedded in paraffin for sectioning. Sections were prepared, and hematoxylin and eosin (H\&E) staining and Grocott staining were carried out by standard protocols.

\section{RESULTS}

Targeted disruption of the mouse Mpo gene. The targeting strategy used to disrupt the $M p o$ coding sequence is illustrated 

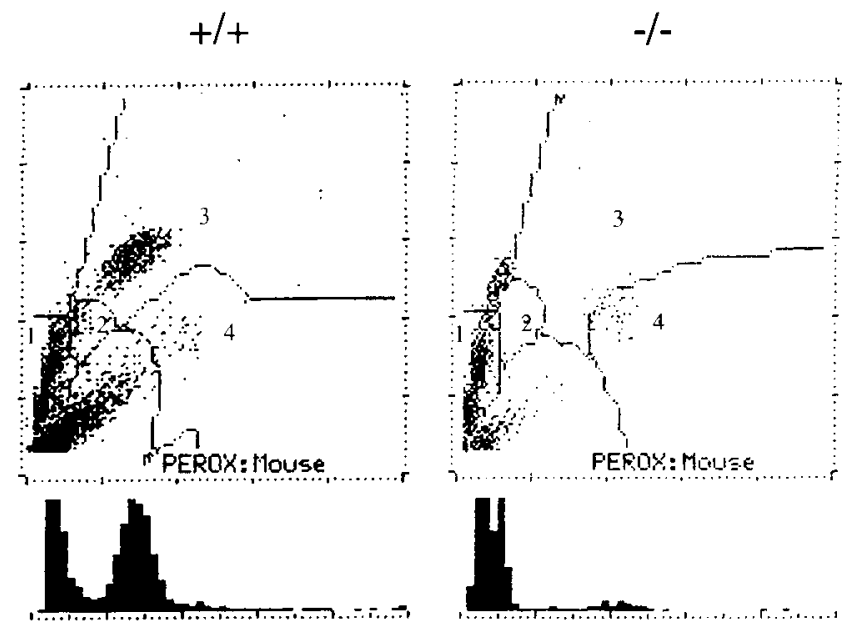

FIG. 2. Leukograms of Technicon H-1 analysis of wild-type $(+/+)$ and homozygous mutant $(-/-)$ mice. Light scattering is plotted on the $y$ axis, and peroxidase (PEROX) activity is plotted on the $x$ axis. The numbers indicate the following cells: 1 , lymphocytes; 2 , monocytes; 3 , neutrophils; 4 , eosinophils. The lower the peroxidase activity of a single cell, the more the cell is located toward the left on the $x$ axis. Histograms of peroxidase activity are shown below the graphs.

in Fig. 1A. The targeting vector was constructed by removing a 0.7-kb $X b a \mathrm{I}-E c o$ RI fragment containing exon 6 through a part of intron 7 and replacing it with the neo gene. In addition, a copy of the HSV TK gene was placed at the $3^{\prime}$ end of the construct. Both of the selectable marker genes were inserted in the same transcriptional orientation as the Mpo gene. Male chimeric mice generated by use of correctly targeted ES cells transmitted the mutation of the Mpo gene through the germ line when mated with C57BL/6 female mice (Fig. 1B). Heterozygote $\left(\mathrm{Mpo}^{+/-}\right)$mating then produced homozygous mutant mice $\left(\mathrm{Mpo}^{-1-}\right)$ at the expected Mendelian frequency. The mutant mice were viable, exhibited normal growth and development, and were fertile. As shown in Fig. 1C, Northern blot analysis of mRNA isolated from the bone marrow of homozygous mutant mice showed no significant hybridization to the human $M P O$ cDNA probe, whereas the bone marrow of wildtype mice $\left(\mathrm{Mpo}^{+/+}\right)$contained mRNA for $\mathrm{Mpo}$, indicating the absence of any detectable transcript for the Mpo gene in the mutants. The heterozygous mice showed the expected $50 \%$ reduction in mRNA levels.

Identification of MPO-deficient neutrophils and monocytes. Figure 2 shows the leukograms for the peroxidase activity of peripheral blood cells from wild-type and homozygous mutant mice determined with Technicon $\mathrm{H}-1$. When stained vesicles are lacking, the light scattering changes characteristically, leading to a cluster location upward on the $y$ axis and a shift to the left on the $x$ axis. The neutrophil clusters from homozygous mutant mice clearly shifted to the left, unstained cell area, and no stained cells were observed in the normal neutrophil area. The mutant mice also showed no clusters in the monocyte area. These results strongly suggested that the neutrophils and the monocytes of the homozygous mice that we generated are completely deficient in MPO. However, the clusters of their eosinophils did not shift to the left, demonstrating that eosinophil peroxidase is genetically distinct from MPO.

MPO activity in peritoneal exudate neutrophils. In order to explore MPO deficiency in further detail, neutrophils were isolated from the thioglycolate-injected peritoneal cavity of wild-type, heterozygous, and homozygous mice. Judging from the microscopic examination of Wright-Giemsa-stained samples, more than $95 \%$ of the exudate cells recovered $4 \mathrm{~h}$ after injection were neutrophils, regardless of their genotypes. Cytochemical staining with TMB revealed that more than $95 \%$ of the exudate cells in wild-type and heterozygous mice were peroxidase positive (Fig. 3A). In contrast, the majority of homozygous mutant mice were peroxidase negative. Quantitative analysis by spectrophotometry demonstrated that the average MPO activity in wild-type mice was $1.7 \mathrm{nmol} / \mathrm{min} / 10^{6}$ cells (Fig. $3 \mathrm{~B})$. Heterozygous animals showed the expected $50 \%$ reduction in MPO activity. Homozygous mutant mice showed only a low level of MPO activity. This low level of activity likely represents peroxidase activity supplied by eosinophils, because eosinophil peroxidase is normally active in homozygous mutant mice (Fig. 2) and is able to oxidize TMB. From these results, we conclude that homozygous mutant mice have no detectable MPO activity, while heterozygous mice have half the level of MPO activity present in wild-type littermates.

$\mathrm{HOCl}$ and $\mathrm{O}_{2}{ }^{-}$generation from normal and MPO-deficient neutrophils. During the respiratory burst, neutrophils generate
A

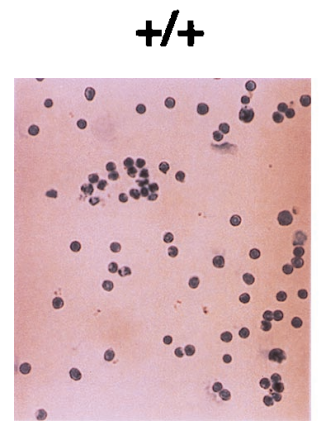

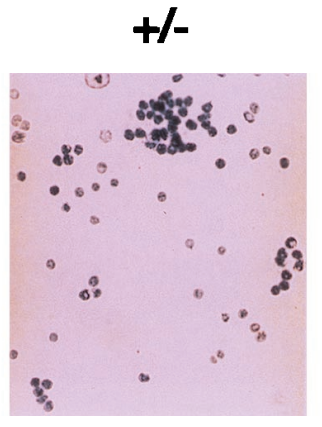

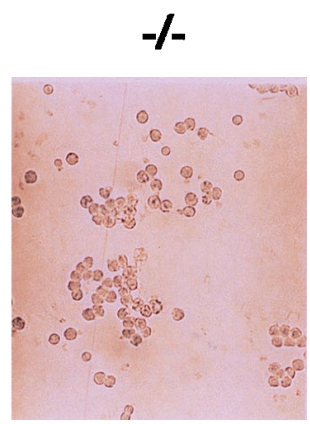

B

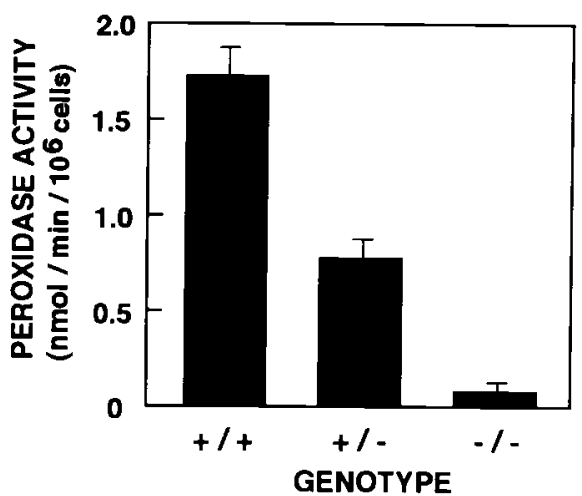

FIG. 3. MPO activity of neutrophils. Wild-type $(+/+)$, heterozygous mutant $(+/-)$, and homozygous mutant $(-/-)$ mice were injected with thioglycolate in the peritoneal cavity, and peritoneal exudate cells were collected $4 \mathrm{~h}$ later. (A) The cells were fixed and stained with TMB for peroxidase activity. (B) Peroxidase activities in total peritoneal exudate cells were measured with TMB as a substrate. Three animals of different genotypes, each tested in duplicate, were used. Results represent means \pm standard deviations. 


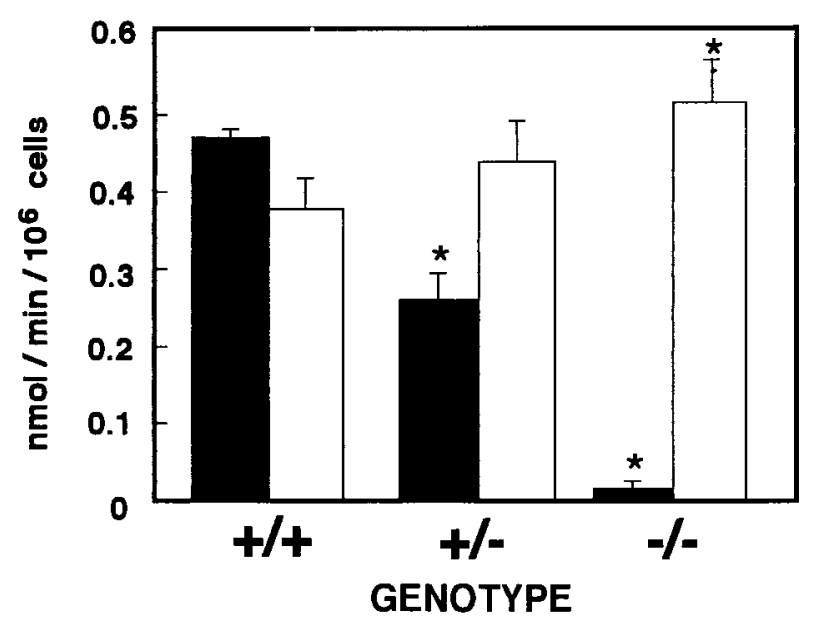

FIG. 4. $\mathrm{HOCl}$ and $\mathrm{O}_{2}{ }^{-}$generation from neutrophils of wild-type $(+/+)$, heterozygous mutant $(+/-)$, and homozygous mutant $(-/-)$ mice. The levels of $\mathrm{HOCl}$ (closed bars) and $\mathrm{O}_{2}{ }^{-}$(open bars) generated from PMA-stimulated peritoneal exudate neutrophils $\left(2 \times 10^{5}\right.$ cells $)$ were determined by the chlorination of MCD and the SOD-inhibitable reduction of cytochrome $c$, respectively. Three animals of each genotype were used in each experiment, and assays were performed in triplicate. Results represent means \pm standard deviations. The asterisk indicates a $P$ value of $<0.05$ for mutant versus wild-type mice, as determined by Student's $t$ test.

$\mathrm{O}_{2}{ }^{-}$via the NADPH oxidase system. $\mathrm{O}_{2}{ }^{-}$is then reduced to $\mathrm{H}_{2} \mathrm{O}_{2}$, from which $\mathrm{HOCl}$ is generated by the MPO reaction.

The rapid reaction of $\mathrm{MCD}$ with $\mathrm{HOCl}$ to form dichlorodimedon (21) was used to determine the level of $\mathrm{HOCl}$ generation from the peritoneal exudate neutrophils (Fig. 4). The average level of $\mathrm{HOCl}$ generation from wild-type neutrophils was $0.47 \mathrm{nmol} / \mathrm{min} / 10^{6}$ cells. On the other hand, as anticipated from the absence of peroxidase activity (Fig. 2 and 3), the neutrophils of homozygous mutant mice produced $\mathrm{HOCl}$ at an almost undetectable level. Because EPO also produces $\mathrm{HOCl}$ from $\mathrm{H}_{2} \mathrm{O}_{2}$, a low level of $\mathrm{HOCl}$ detected in homozygous mutant mice could be supplied from eosinophils. The neutrophils of heterozygous mutant mice generated from half the normal level of $\mathrm{HOCl}$. These results demonstrate that the levels of $\mathrm{HOCl}$ generated from the neutrophils in each genotype correlate well with the MPO activities measured with TMB as a substrate (Fig. 3).

$\mathrm{O}_{2}{ }^{-}$generation by peritoneal exudate neutrophils was measured as SOD-inhibitable cytochrome $c$ reduction. The average level of $\mathrm{O}_{2}{ }^{-}$generation from neutrophils of wild-type mice was $0.39 \mathrm{nmol} / \mathrm{min} / 10^{6}$ cells (Fig. 4) and was completely inhibited in the presence of SOD (data not shown). The neutrophils of homozygous mutant mice generated a slightly higher level of $\mathrm{O}_{2}{ }^{-}\left(0.50 \mathrm{nmol} / \mathrm{min} / 10^{6}\right.$ cells $)$ than did those of wild-type mice $(P,<0.05)$ (Fig. 4). A slight enhancement of $\mathrm{O}_{2}{ }^{-}$generation was also seen in heterozygous mutant mice, although it did not reach statistical significance $(P, 0.075)$.

Clearance of $S$. aureus in vivo. To assess whether MPOdeficient mice have enhanced susceptibility to $S$. aureus infection in vivo, mice were intraperitoneally challenged with $7 \times$ $10^{7}$ cells of $S$. aureus. Most of the cells injected disappeared by $48 \mathrm{~h}$ both in wild-type and in homozygous mutant mice, and there was no difference in the rates of clearance between those mice (Fig. 5). Gross anatomical experiments revealed no obvious inflammation of the lungs, liver, heart, kidneys, and intestines.

Pulmonary infection with $\boldsymbol{C}$. albicans. To investigate the susceptibility of MPO-deficient mice to C. albicans compared

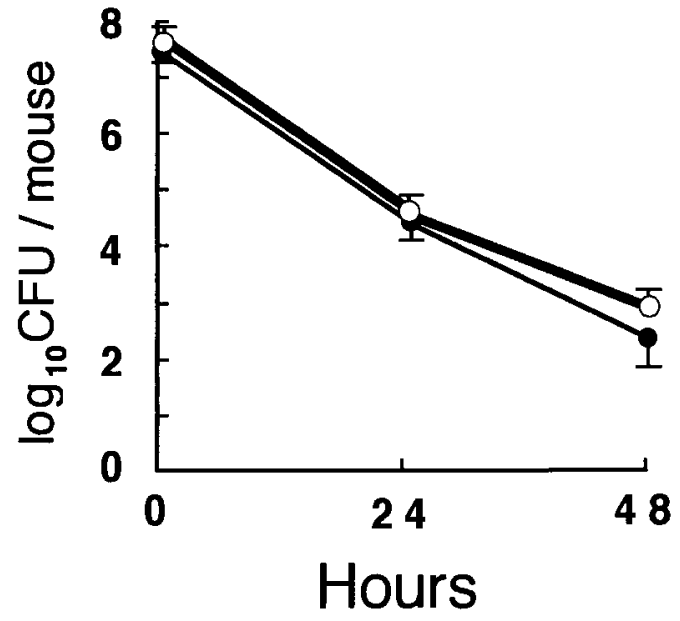

FIG. 5. Clearance of viable $S$. aureus from the peritoneal cavity. Peritoneal exudate fluid was cultured 24 and $48 \mathrm{~h}$ after intraperitoneal injection of $7 \times 10^{7}$ CFU of $S$. aureus. Results represent mean $\log _{10}$ CFU \pm standard deviations obtained from three to five wild-type mice (closed circles) and homozygous mutant mice (open circles).

to that of wild-type littermates, 26 wild-type, 18 heterozygous mutant, and 27 homozygous mutant mice were challenged with $4 \times 10^{6}$ fungi intratracheally. This is a relatively low dose, since the $50 \%$ lethal dose for mice challenged by the intratracheal route was estimated to be in excess of $10^{8}$ yeast cells by Sawyer (42). On the following day, signs of severe infection, including ruffled fur and hunched posture, were observed only in the homozygous mutant mice. The wild-type mice were able to eliminate the fungi effectively, and approximately 2,000 fungi were recovered from their lungs $120 \mathrm{~h}$ after infection (Fig. 6A). In contrast, in the mutant mice, the clearance of viable $C$. albicans was significantly delayed, and nearly 500 times as many viable fungi were cultured from their lungs (Fig. 6A). In addition, the survival of the mutant mice was dramatically decreased, and 18 of the 27 mice died by 5 days after the challenge. We also determined the numbers of viable C. albicans cultured from other tissues. In the kidneys (Fig. 6B), the number of $C$. albicans in the wild-type mice was almost below the detectable level, whereas that in the homozygous mutant mice was time dependently increased, and about 6,000 fungi were detected at $120 \mathrm{~h}$. In the brain, heart, and liver of both wild-type and homozygous mutant mice, the numbers of $C$. albicans were all below 100 fungi per each organ from 20 to 120 h. C. albicans was not detectable in the spleen. There was no difference in the numbers of viable fungi obtained from the mutant mice that had died or that had been weakened. Although the clearance of fungi from the lungs in the heterozygous mutant mice was slightly delayed at $80 \mathrm{~h}$ compared to that in the wild-type mice, almost the same number of fungi disappeared by $120 \mathrm{~h}$ (Fig. 6A).

Only one wild-type mouse died 3 days after the challenge as a consequence of lung bleeding, but no gross or histological abnormalities were observed in the lungs of this mouse or those of the wild-type mice still alive by $120 \mathrm{~h}$ (Fig. 7A and B). In contrast, the lungs of the mutant mice $120 \mathrm{~h}$ after the challenge showed diffuse enlargement and brownish discoloration (Fig. 7A). Additionally, patchy white, soft, and spherical masses 1 to $5 \mathrm{~mm}$ in diameter were observed on the surfaces of every lobe (Fig. 7A). H\&E-stained sections of the lungs revealed massive infiltration of alveolar and peribronchiolar spaces with neutrophil polymorphonuclear leukocytes, and 

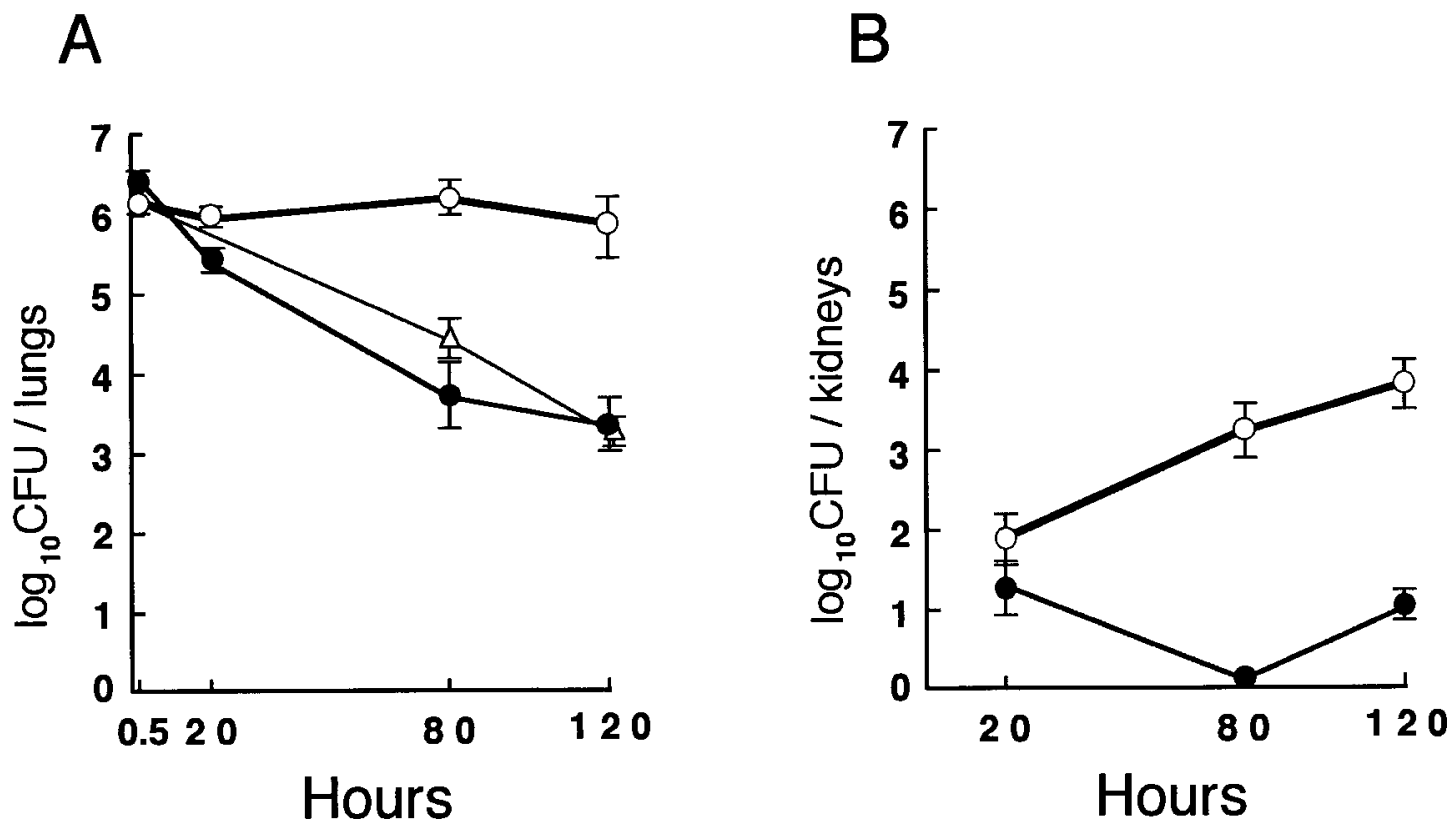

FIG. 6. Pulmonary infection with C. albicans in wild-type, heterozygous mutant, and homozygous mutant mice. Wild-type (closed circles), heterozygous mutant (open triangles), and homozygous mutant (open circles) mice were injected intratracheally with $4 \times 10^{6} \mathrm{CFU}$ of $C$. albicans. At the indicated times after the challenge, whole lungs (A) and kidneys (B) were homogenized, and aliquots of the homogenates were plated on Guanofuracin-Sabouraud agar plates. Five mice or more were used in each group. Results represent mean $\log _{10}$ CFU per organ \pm standard deviations.

fairly extensive edema filled many other alveolar spaces (Fig. 7C). In peribronchiolar spaces around neutrophil infiltrates, mucus infiltration was also observed. Furthermore, some of the peribronchial epithelial cells were observed to be peeling off (Fig. 7D). By Grocott staining, hyphae of C. albicans were detected in several alveolar spaces of the mutant mice (Fig. $7 \mathrm{E}$ ) but not the wild-type mice (data not shown). These clinical features are characteristic of alveolar and peribronchiolar pneumonia, and the most likely explanation for the death of the mutant mice infected with $C$. albicans is severe impairment of lung functions caused by myeloid cell infiltration and edema.

Systemic infection with $C$. albicans via the intraperitoneal route. To evaluate the susceptibility of wild-type and MPOdeficient mice, $C$. albicans was administered intraperitoneally at a dose of $4 \times 10^{6}$ fungi/mouse. Seven days later, the lungs, brain, kidneys, spleen, and liver were removed from five animals in each group and pooled to determine the dissemination of the fungi into these organs. Gross anatomical evaluation revealed no obvious inflammation in any of those organs. In the wild-type mice, the highest and lowest numbers of fungi were found in the liver and the brain, respectively (Fig. 8), consistent with a previous report (20). In contrast, significantly higher numbers of fungi were disseminated into every organ in the homozygous mutant mice, and approximately 290, 11, 110, 17 , and 10 times as many viable fungi were cultured from the lungs, brain, kidneys, spleen, and liver, respectively (Fig. 8). Unlike the results of the intratracheal infection, no obvious signs of severe infection were observed in either wild-type or homozygous mutant mice during a period of 7 days after the challenge. When mice were challenged intraperitoneally at a high dose $\left(10^{8}\right.$ fungi/mouse), all homozygous mutant mice died by 2 days, while all wild-type mice survived for 7 days without many signs of distress. These results demonstrate that MPO is very important for the murine host defense against $C$. albicans and that the lack of MPO enhances $C$. albicans dissemination, especially into the lungs and kidneys.

\section{DISCUSSION}

MPO-deficient mice generated by disruption of the Mpo locus by homologous recombination represent the first genetically defined model for the inherited human MPO deficiency. The mutation disrupts the Mpo gene and completely eliminates expression of the gene, as demonstrated by the absence of the mRNA in the bone marrow and of enzyme activity in the neutrophils and monocytes of homozygous mutant mice. No $\mathrm{HOCl}$ generation by neutrophils in homozygous mutant mice was observed. $\mathrm{O}_{2}{ }^{-}$generation was slightly increased in our MPO-deficient mice, consistent with the deficiency in humans $(22,41)$. Heterozygous mutant mice had half the normal levels of mRNA, enzyme activity, and $\mathrm{HOCl}$ generation.

Homozygous mutant mice completely lacking MPO activity are born and develop normally but exhibited markedly enhanced susceptibility to infection with C. albicans. Mutant mice intratracheally exposed to even a low dose of $C$. albicans developed severe alveolar and peribronchiolar pneumonia (Fig. 7) resulting in the death of two-thirds of the mice. Although this challenge was time dependently disseminated into the kidneys (Fig. 6B), this process was unlikely to be the main cause of death, because mice intraperitoneally infected with $C$. albicans were in good health for at least 7 days even when a slightly higher number of fungi was present in the kidneys (Fig. 8 ). Rather, the severe pneumonia was more likely to be the main cause of death of the mutant mice intratracheally challenged with $C$. albicans. It is well known that MPO plus $\mathrm{H}_{2} \mathrm{O}_{2}$ plus $\mathrm{Cl}^{-}$forms a cytotoxic triad in vitro which is toxic for fungi $(9,49)$ and that neutrophils genetically deficient in MPO fail to kill them (37). In addition, neutrophils are often the first cells to be recruited to a site of infection, where they show a higher level of phagocytic activity against $C$. albicans than do alveolar macrophages (26). Taken together, the results indicate that it is most plausible that neutrophils with MPO represent the early stage of defense in the lungs against $C$. albicans and that 


\section{A}

$+1+$

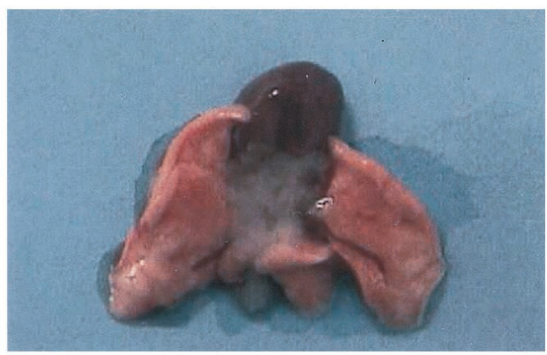

- / -

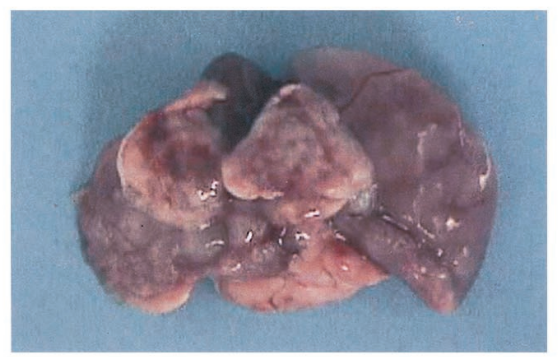

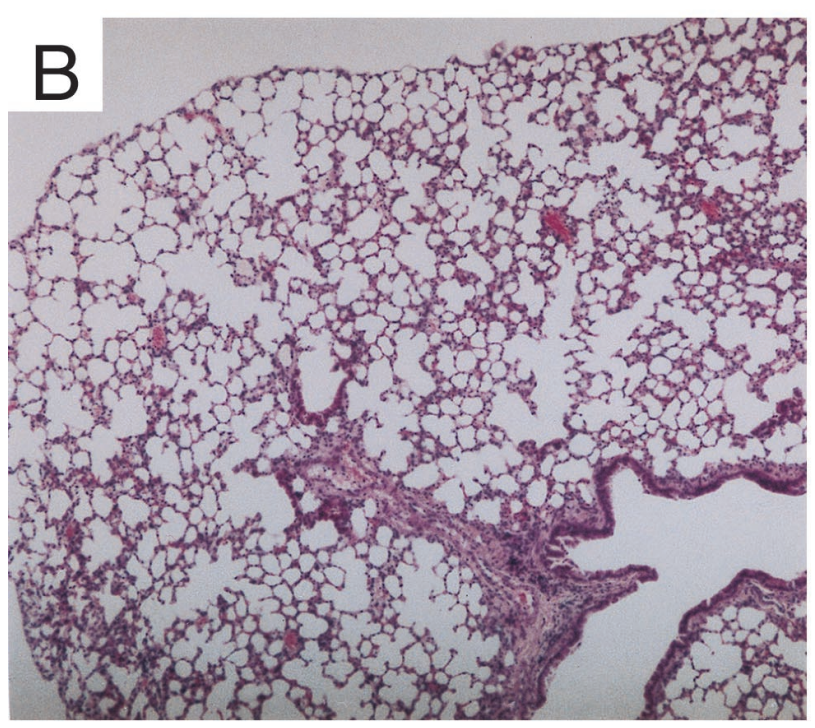
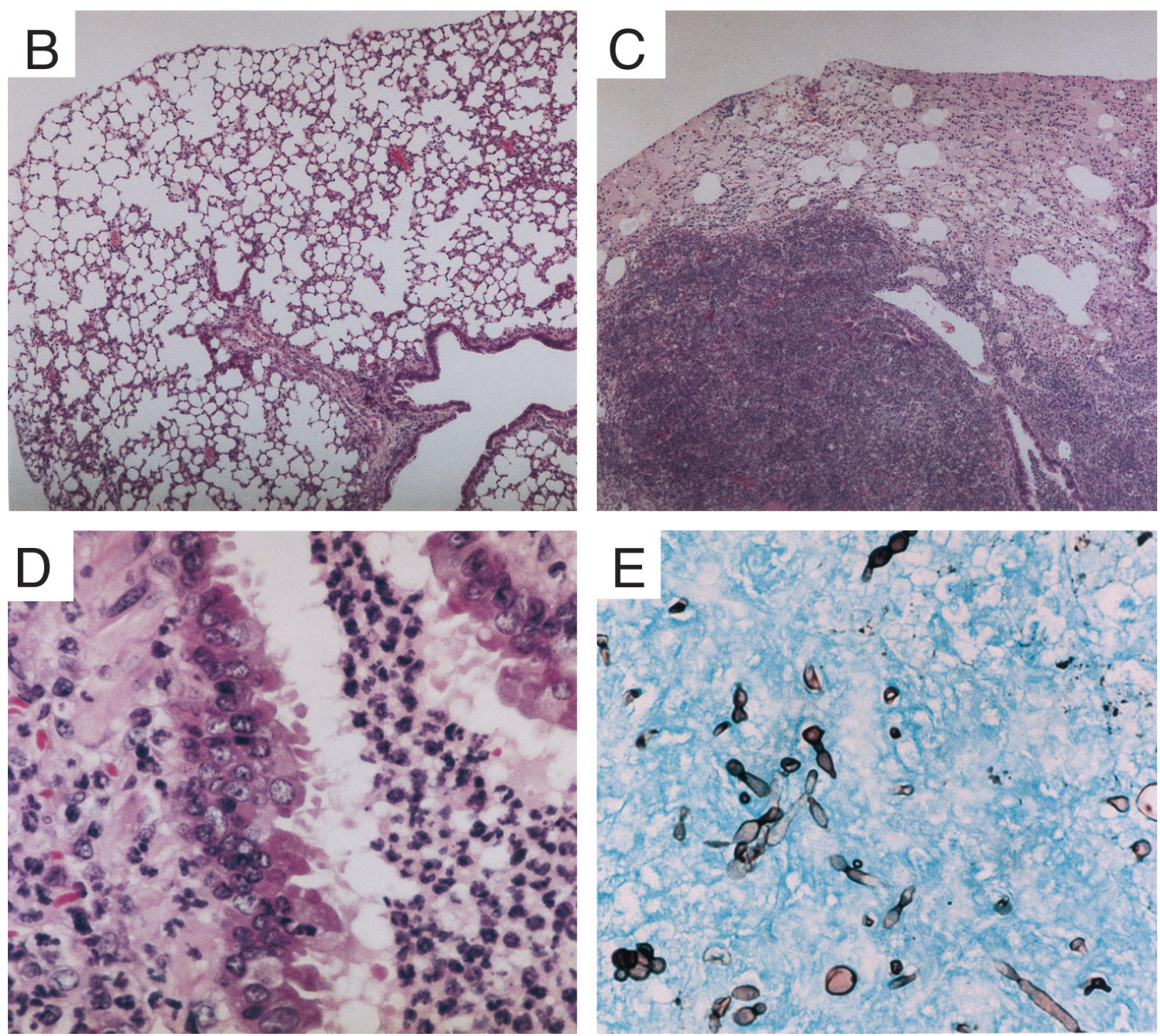

FIG. 7. Lung pathology observed in wild-type and homozygous mutant mice $120 \mathrm{~h}$ after intratracheal challenge with $C$. albicans. (A) Representative gross appearance of lungs from wild-type $(+/+)$ and homozygous mutant $(-/-)$ mice. (B) H\&E-stained section from a wild-type mouse. Magnification, $\times 40$. (C) H\&E-stained section from a representative homozygous mutant mouse. Magnification, $\times 40$. (D) Same sample as $\mathrm{C}$ but at a magnification of $\times 400$. (E) Grocott-stained section from a homozygous mutant mouse. Magnification, $\times 400$. 


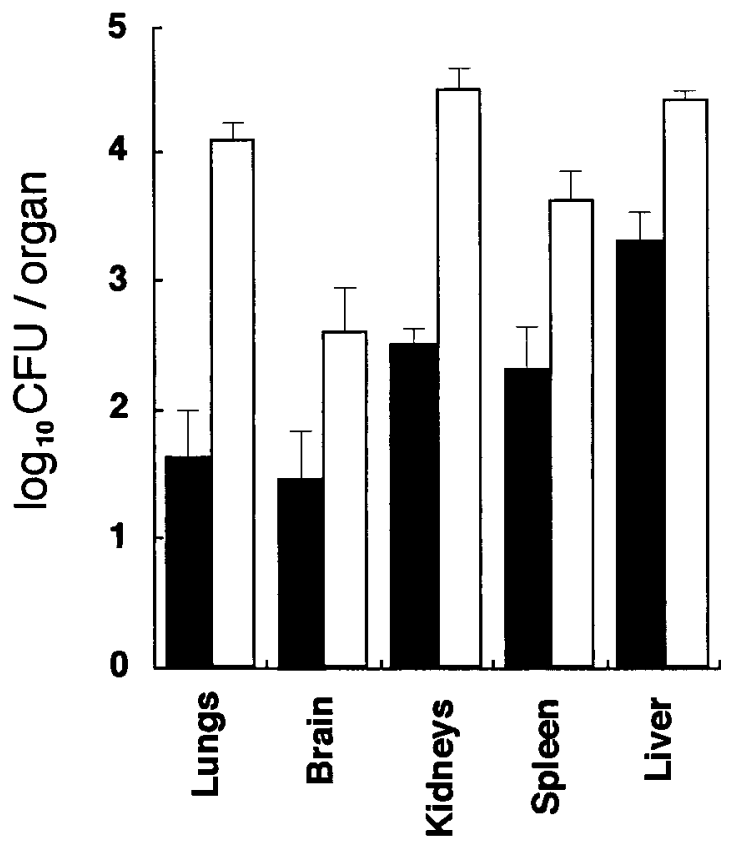

FIG. 8. Numbers of C. albicans cultured from various organs of mice after intraperitoneal challenge. Wild-type mice (closed bars) and homozygous mutant mice (open bars) were injected intraperitoneally with $4 \times 10^{6}$ cells of $C$. albicans. Seven days after the challenge, the organs were removed and homogenized, and aliquots of the homogenates were plated on Guanofuracin-Sabouraud agar plates. Five mice were used in each group. Results represent mean $\log _{10} \mathrm{CFU}$ per organ \pm standard deviations.

inefficient killing due to the lack of MPO causes a continuous recruitment of neutrophils into the lungs, leading to congestion of the lungs.

Heterozygous mice, having about half the normal level of MPO activity (Fig. 3 and 4), showed only a slight delay in the killing of $C$. albicans in the lungs compared to that in wild-type mice at the tested dose (Fig. 6). These results strongly suggest that $\mathrm{HOCl}$ produced from neutrophils at half the normal rate could be sufficient in vivo for exhibiting complete fungal killing. Alternatively, neutrophils with normal and suboptimal MPO activities may equally enhance secondary antifungal effector activities, such as that of macrophages. Although alveolar macrophages are less able to kill C. albicans than neutrophils (26), those exposed to MPO are known to exhibit an enhanced respiratory burst (30), resulting in augmentation of the macrophage-mediated cytotoxicity for $C$. albicans $(28,33)$. Furthermore, MPO stimulates macrophages to secrete cytokines, such as tumor necrosis factor alpha (27), which causes neutrophils to degranulate and to release more MPO into the microenvironment and which potentiates Candida killing by neutrophils in vitro (13). Hence, a feedback loop is established until the pathogen is removed. Further studies on the susceptibility of heterozygous mice with strain backgrounds different from 129/C57BL to various doses of fungi are important to clarify the risk of patients with partial MPO deficiency for fungal infection.

The increase in fungal load found in the lungs, brain, kidneys, spleen, and liver of systemically infected MPO-deficient mice may imply a possible unique role for MPO against Candida infection in each organ. Among the organs, the lungs and the kidneys were most affected by the lack of MPO, while the other organs were less affected. It has been reported that depletion of neutrophils in mice increases the susceptibility to systemic infection with $C$. albicans and that the fungal burden in the kidneys increases 100 -fold on day 4, while the brain is little affected (15). Our results obtained with MPO-deficient mice are similar to those obtained with neutrophil-depleted mice (15). Furthermore, intraperitoneal administration of purified MPO has been reported to increase the resistance of mice to Candida infection (50), suggesting that peritoneal neutrophils without MPO are impaired in their ability to protect against invasion from the intraperitoneal route. Collectively, these results indicate that neutrophils with MPO play a critical role against systemic candidiasis, especially in the lungs and kidneys, while other defense systems, such as the phagocytic function of macrophages, appear to be more effective in the brain, spleen, and liver.

When homozygous mutant mice were challenged with the same dose of $C$. albicans $\left(4 \times 10^{6}\right.$ fungi/mouse) by different routes (intratracheal and intraperitoneal), the mice showed a higher level of resistance to challenge by the intraperitoneal route, and no death occurred within 7 days. As peritoneal macrophages have higher levels of phagocytic activity than do alveolar macrophages (48), the mechanism of resistance may be due to the presence of an environment rich in macrophage activity in the area where the systemic invasion is prevented or delayed by phagocytosis.

Homozygous mutant mice did not exhibit a remarkable difference from wild-type mice in the rate of clearance of $S$. aureus from the peritoneal cavity (Fig. 5). This finding is consistent with the fact that most humans deficient in MPO show no symptoms and with the observations that although the in vitro killing of $S$. aureus in MPO-deficient neutrophils is significantly less effective than normal at early time periods, it reaches the normal rate by approximately $1 \mathrm{~h}$ (37) or $2 \mathrm{~h} \mathrm{(22)}$ after the organism is ingested. The lack of impairment in the clearance of $S$. aureus in our homozygous mutant mice in vivo is also in clear contrast to the results obtained with a mouse model of CGD; because of a mutation in the NADPH oxidase gene, these mice are unable to generate $\mathrm{O}_{2}{ }^{-}$, and the clearance of $S$. aureus from the peritoneal cavity is retarded (38). It is thus likely that reactive oxygen species other than $\mathrm{HOCl}$, such as $\mathrm{O}_{2}{ }^{-}$, are sufficient for neutrophils to kill $S$. aureus. Further studies with MPO-deficient mice are warranted to define the role of MPO in S. aureus infection.

Oxidants generated by neutrophils and monocytes have been implicated in the tissue damage that occurs when these phagocytic cells penetrate tissue in various chronic inflammatory conditions (10-12). However, to date there is a lack of convincing evidence that the MPO- $\mathrm{H}_{2} \mathrm{O}_{2}-\mathrm{Cl}^{-}$system causes tissue injury in chronic inflammation in vivo. MPO-deficient mice should therefore be invaluable for evaluating the role of phagocyte-derived oxidants not only in host defense against various pathogens but also in tissue injury and resolution of the inflammatory response and for refining treatment strategies.

\section{ACKNOWLEDGMENTS}

We thank Hideki Kajiwara of Bayer-Sankyo Co. Ltd. for the operation of Technicon H-1, Michiyuki Yamada for providing the human $M P O$ cDNA (pH17), Hisayoshi Akagawa and Yukie Takano for providing C. albicans, Syntex Inc. for supplying ganciclovir, Yoji Nagashima for helpful discussions, Ayako Onuma for animal care, and Hyung-Suk Kim and Akiko Okawara for performing preliminary experiments. We especially thank Oliver Smithies for enthusiastic encouragement.

This work was supported by grants in support of the promotion of research at Yokohama City University to Y.A. and NIH grant HL42630 to N.M. 


\section{REFERENCES}

1. Andrews, P. C., and N. I. Krinsky. 1981. The reductive cleavage of myeloperoxidase in half, producing enzymically active hemi-myeloperoxidase. J. Biol. Chem. 256:4211-4218.

2. Badwey, J. A., and M. L. Karnovsky. 1980. Active oxygen species and the functions of phagocytic leukocytes. Annu. Rev. Biochem. 49:695-726.

3. Bainton, D. F., J. L. Ullyot, and M. G. Farquhar. 1971. The development of neutrophilic polymorphonuclear leukocytes in human bone marrow. J. Exp. Med. 134:907-934.

4. Belaaouaj, A., R. McCarthy, M. Baumann, Z. Gao, T. J. Ley, S. N. Abraham, and S. D. Shapiro. 1998. Mice lacking neutrophil elastase reveal impaired host defense against gram negative bacterial sepsis. Nat. Med. 4:615-618.

5. Bradley, P. P., R. D. Christensen, and G. Rothstein. 1982. Cellular and extracellular myeloperoxidase in pyogenic inflammation. Blood 60:618-622.

6. Cech, P., H. Stalder, J. J. Widmann, A. Rohner, and P. A. Miescher. 1979. Leukocyte myeloperoxidase deficiency and diabetes mellitus associated with Candida albicans liver abscess. Am. J. Med. 66:149-153.

7. Clark, R. A., and S. Szot. 1981. The myeloperoxidase-hydrogen peroxidehalide system as effector of neutrophil-mediated tumor cell cytotoxicity. J. Immunol. 126:1295-1301.

8. Cramer, R., M. R. Soranzo, P. Dri, G. D. Rottini, M. Bramezza, S. Cirielli, and P. Patriarca. 1982. Incidence of myeloperoxidase deficiency in an area of northern Italy: histochemical, biochemical and functional studies. Br. J. Hematol. 51:81-87.

9. Diamond, R. D., R. A. Clark, and C. C. Haudenschild. 1980. Damage to Candida albicans hyphae and pseudohyphae by the myeloperoxidase system and oxidative products of neutrophil metabolism in vitro. J. Clin. Investig. 66:908-917.

10. Domigan, N. M., T. S. Charlton, M. W. Duncan, C. C. Winterbourn, and A. J. Kettle. 1995. Chlorination of tyrosyl residues in peptides by myeloperoxidase and human neutrophils. J. Biol. Chem. 270:16542-16548.

11. Eiserich, J. P., C. E. Cross, A. D. Jones, B. Halliwell, and A. Vliet. 1996. Formation of nitrating and chlorinating species by reaction of nitrite with hypochlorous acid. J. Biol. Chem. 271:19199-19208.

12. Eiserich, J. P., M. Hristova, C. E. Cross, A. D. Jones, B. A. Freeman, B. Halliwell, and A. Vliet. 1998. Formation of nitric oxide-derived inflammatory oxidants by myeloperoxidase in neutrophils. Nature 391:393-397.

13. Ferrante, A. 1989. Tumor necrosis factor alpha potentiates neutrophil antimicrobial activity: increased fungicidal activity against Torulopsis glabrata and Candida albicans and associated increases in oxygen radical production and lysosomal enzyme release. Infect. Immun. 57:2115-2122.

14. Fridovich, I. 1985. Cytochrome c, p. 121-122. In R. A. Greenwald (ed.), Handbook of methods for oxygen radical research. CRC Press, Inc., Boca Raton, Fla.

15. Fulurija, A., R. B. Ashman, and J. M. Papadimitriou. 1996. Neutrophil depletion increases susceptibility to systemic and vaginal candidiasis in mice, and reveals differences between brain and kidney in mechanisms of host resistance. Microbiology 142:3487-3496.

16. Hager, L. P., D. R. Morris, F. S. Brown, and H. Eberwein. 1966. Chloroperoxidase. J. Biol. Chem. 241:1769-1777.

17. Hashinaka, K., C. Nishio, S.-J. Hur, F. Sakiyama, S. Tsunasawa, and M. Yamada. 1988. Multiple species of myeloperoxidase messenger RNAs produced by alternative splicing and differential polyadenylation. Biochemistry 27:5906-5914.

18. Hazen, S. L., and J. W. Heinecke. 1997. 3-Chlorotyrosine, a specific marker of myeloperoxidase-catalyzed oxidation, is markedly elevated in low density lipoprotein isolated from human atherosclerotic intima. J. Clin. Investig. 99:2075-2081.

19. Johnson, K., I. Gemperlein, S. Hudson, S. Shane, and G. Rovera. 1989. Complete nucleotide sequence of the human myeloperoxidase gene. Nucleic Acids Res. 17:7985-7986.

20. Káposzta, R., P. Tree, L. Maródi, and S. Gordon. 1998. Characteristics of invasive candidiasis in gamma interferon- and interleukin-4-deficient mice: role of macrophages in host defense against Candida albicans. Infect. Immun. 66:1708-1717

21. Kettle, A. J., and C. C. Winterbourn. 1990. Superoxide enhances hypochlorous acid production by stimulated human neutrophils. Biochim. Biophys. Acta 1052:379-385.

22. Kitahara, M., H. J. Eyre, Y. Simonian, C. L. Atkin, and S. J. Hasstedt. 1981. Hereditary myeloperoxidase deficiency. Blood 57:888-893.

23. Klebanoff, S. J. 1991. Myeloperoxidase: occurrence and biological function, p. 1-35. In E. Johannes, E. E. Kathleen, and B. G. Mathaw (ed.), Peroxidase in chemistry and biology. CRC Press, Inc., Boca Raton, Fla.

24. Klebanoff, S. J., and R. W. Coombs. 1992. Viricidal effect of polymorphonuclear leukocytes on human immunodeficiency virus-1. Role of the myeloperoxidase system. J. Clin. Investig. 89:2014-2017.

25. Koller, B. H., L. J. Hagemann, T. Doetschman, J. R. Hagaman, S. Huang, P. J. Williams, N. L. First, N. Maeda, and O. Smithies. 1989. Germ-line transmission of a planned alteration made in a hypoxanthine phosphoribosyltransferase gene by homologous recombination in embryonic stem cells. Proc. Natl. Acad. Sci. USA 86:8927-8931.
26. Lal, S., M. Mitsuyama, M. Miyata, N. Ogata, K. Amako, and K. Nomoto. 1986. Pulmonary defence mechanism in mice. A comparative role of alveolar macrophages and polymorphonuclear cells against infection with Candida albicans. J. Clin. Lab. Immunol. 19:127-133.

27. Lefokowitz, D. L., K. Mills, D. Morgan, and S. S. Lefokowitz. 1992. Macrophage activation and immunomodulation by myeloperoxidase. Proc. Soc. Exp. Biol. Med. 199:204-210.

28. Lefokowitz, S. S., M. P. Gelderman, D. L. Lefokowitz, N. Moguilevsky, and A. Bollen. 1996. Phagocytosis and intracellular killing of Candida albicans by macrophages exposed to myeloperoxidase. J. Infect. Dis. 173:1202-1207.

29. Lehrer, R. I., and M. J. Cline. 1969. Leukocyte myeloperoxidase deficiency and disseminated candidiasis: the role of myeloperoxidase in resistance to Candida infection. J. Clin. Investig. 48:1478-1488.

30. Lincoln, J. A., D. L. Lefokowitz, T. Cain, A. Castro, K. C. Mills, S. S. Lefokowitz, N. Moguilevsky, and A. Bollen. 1995. Exogenous myeloperoxidase enhances bacterial phagocytosis and intracellular killing by macrophages. Infect. Immun. 63:3042-3047

31. London, S. J., T. A. Lehman, and J. A. Taylor. 1997. Myeloperoxidase genetic polymorphism and lung cancer risk. Cancer Res. 57:5001-5003.

32. Mansour, S. L., K. R. Thomas, and M. R. Capecchi. 1988. Disruption of the proto-oncogene int-2 in mouse embryo-derived stem cells: a general strategy for targeting mutations to non-selectable genes. Nature 336:348-352.

33. Maródi, L., C. Tournay, R. Káposzta, R. B. Johnston, and N. Moguilevsky. 1998. Augmentation of human macrophage candidacidal capacity by recombinant human myeloperoxidase and granulocyte-macrophage colony-stimulating factor. Infect. Immun. 66:2750-2754.

34. Nauseef, W. M., M. Cogley, S. Bock, and P. E. Petrides. 1998. Pattern of inheritance in hereditary myeloperoxidase deficiency associated with the R569W missense mutation. J. Leukocyte Biol. 63:264-269.

35. Nguyen, C., and H. P. Katner. 1997. Myeloperoxidase deficiency manifesting as pustular candida dermatitis. Clin. Infect. Dis. 24:258-260.

36. Olsen, R. L., and C. Little. 1984. Studies of the subunits of human myeloperoxidase. Biochem. J. 222:701-709.

37. Parry, M. F., R. K. Root, J. A. Metcalf, K. K. Delaney, L. S. Kaplow, and W. J. Richar. 1981. Myeloperoxidase deficiency. Ann. Intern. Med. 95:293301.

38. Pollock, J. D., D. A. Williams, M. A. C. Gifford, L. L. Li, X. Du, J. Fisherman, S. H. Orkin, C. M. Doerschuk, and M. C. Dinauer. 1995. Mouse model of $\mathrm{X}$-linked chronic granulomatous disease, an inherited defect in phagocyte superoxide production. Nat. Genet. 9:202-209.

39. Robinson, T. J. D. L. Morris, and D. H. Ledbetter 1990. Chromosomal assignment and regional localization of myeloperoxidase in the mouse. Cytogenet. Cell Genet. 53:83-86.

40. Romano, M., P. Dri, L. Dadalt, P. Patriarca, and F. E. Baralle. 1997. Biochemical and molecular characterization of hereditary myeloperoxidase deficiency. Blood 90:4126-4134.

41. Rosen, H., and S. J. Klebanoff. 1976. Chemiluminescence and superoxide production by myeloperoxidase-deficient leukocytes. J. Clin. Investig. 58:5060.

42. Sawyer, R. T. 1990. Experimental pulmonary candidiasis. Mycopathologia 109:99-109.

43. Stendahl, O., B.-I. Coble, C. Dahlgen, J. Hed, and L. Molin. 1984. Myeloperoxidase modulates the phagocytic activity of polymorphonuclear neutrophil leukocytes. Studies with cells from a myeloperoxidase-deficient patient. J. Clin. Investig. 73:366-373.

44. Sullivan, P. M., H. Mezdour, Y. Aratani, C. Knouff, J. Najib, R. L. Reddick, S. H. Quarfordt, and N. Maeda. 1997. Targeted replacement of the mouse apolipoprotein $\mathrm{E}$ gene with the common human $A P O E 3$ allele enhances diet-induced hypercholesterolemia and atherosclerosis. J. Biol. Chem. 272: $17972-17980$

45. Suzuki, K., H. Ota, S. Sasagawa, T. Sakatani, and T. Fujikura. 1983. Assay method for myeloperoxidase in human polymorphonuclear leukocytes. Anal. Biochem. 132:345-352.

46. Venturelli, D., S. Bittenbender, and G. Rovera. 1989. Sequence of the murine myeloperoxidase (MPO) gene. Nucleic Acids Res. 17:7987-7988.

47. Watanabe, M., J. Osada, Y. Aratani, K. Kluckman, R. Reddick, M. R. Malinow, and N. Maeda. 1995. Mice deficient in cystathionine $\beta$-synthase: animal models for mild and severe homocyst(e)inemia. Proc. Natl. Acad. Sci. USA 92:1585-1589.

48. Weinberg, D. S., and E. R. Unanue. 1981. Antigen-presenting function of alveolar macrophages: uptake and presentation of Listeria monocytogenes. J. Immunol. 126:794-799.

49. Wright, C. D., J. U. Bowie, G. R. Gray, and R. D. Nelson. 1983. Candidacida activity of myeloperoxidase: mechanisms of inhibitory influence of soluble cell wall mannan. Infect. Immun. 42:76-80.

50. Wright, C. D., and R. D. Nelson. 1985. Candidacidal activity of myeloperoxidase: therapeutic influence of the enzyme in vivo. Infect. Immun. 47:363365 .

51. Yamada, M., S. J. Hur, K. Hashinaka, K. Tsuneoka, T. Saeki, C. Nishio, F. Sakiyama, and S. Tsunasawa 1987. Isolation and characterization of a cDNA coding for human myeloperoxidase. Arch. Biochem. Biophys. 255: 147-155. 
52. Yamamoto, K., T. Miyoshi-Koshio, Y. Utsuki, S. Mizuno, and K. Suzuki. 1991. Virucidal activity and viral protein modification by myeloperoxidase: a candidate for defense factor of human polymorphonuclear leukocytes against influenza virus infection. J. Infect. Dis. 164:8-14.

53. Yamamoto, K., K. Suzuki, K. Suzuki, and S. Mizuno. 1989. Phagocytosis and ingestion of influenza virus by human polymorphonuclear leukocytes in vitro. J. Med. Microbiol. 28:91-198.
54. Zaki, S. R., G. E. Austin, W. C. Chan, A. L. Conaty, S. Trusler, S. Trappier, R. B. Lindsey, and D. C. Swan. 1990. Chromosomal localization of the human myeloperoxidase gene by in situ hybridization using oligonucleotide probes. Genes Chromosomes Cancer 2:266-270.

55. Zaki, S. R., G. E. Austin, D. C. Swan, W. C. Hooper, P. W. Greer, B. L. Evatt, and W. C. Chan. 1990. Studies of myeloperoxidase gene expression at the cellular level by in situ hybridization. Leukemia 4:813-818.

Editor: S. H. E. Kaufmann 